\title{
TRÊS CICLOS DE SELEÇÃO ENTRE E DENTRO DE PROGÊNIES DE MEIOS-IRMÃOS NA POPULAÇÃO DE MILHO CMS-521
}

\author{
HÉLIO WILSON LEMOS DE CARVALHO², MARIA DE LOURDES DA SILVA LEAL², \\ PAULO EVARISTO DE OLIVEIRA GUIMARÃES ${ }^{3}$, MANOEL XAVIER DOS SANTOS ${ }^{3}$ \\ e PAULO CÉSAR LEMOS DE CARVALHO ${ }^{4}$
}

\begin{abstract}
RESUMO - Três ciclos de seleção entre e dentro de progênies de meios-irmãos foram praticados na população de milho (Zea mays L.) de alta qualidade protéica CMS-52, nos tabuleiros costeiros dos estados de Sergipe e Bahia, no período de 1995 a 1997, visando à obtenção de uma população melhor adaptada às condições edafoclimáticas da região. As progênies foram avaliadas em látice simples 14 x 14 , com recombinação das progênies superiores, dentro do mesmo ano agrícola, de modo a se obter um ciclo por ano. Os valores dos parâmetros genéticos decresceram do ciclo original para o ciclo I, mantendo-se no ciclo II com magnitudes semelhantes ao ciclo I. As altas magnitudes desses parâmetros genéticos, as altas médias de produtividades das progênies, e o ganho médio esperado com a seleção entre e dentro de progênies, por ciclo de seleção $(12,3 \%)$, mostram o grande potencial da população em responder à seleção, o que permitirá a obtenção de uma população mais produtiva e melhor adaptada às condições edafoclimáticas da região. A magnitude da interação progênies x locais evidenciou a importância de se avaliarem as progênies em mais de um local, para melhorar a eficiência do processo seletivo e obter estimativas mais consistentes dos componentes da variância.
\end{abstract}

Termos para indexação: Zea mays, parâmetros genéticos, variação genética, teste de progênie, seleção, métodos de melhoramento.

\section{THREE CYCLES SELECTION AMONG AND WITHIN HALF SIB PROGENIES IN THE MAIZE POPULATION CMS-52}

\begin{abstract}
Three cycles of selection among and within half-sib progenies were carried out in the high quality protein maize (Zea mays L.) population CMS-52, at the tabuleiros costeiros of Sergipe and Bahia, Brazil, during the period of 1995 to 1997. The work aimed at obtaining a better adapted population for the regional environment. The progenies were evaluated on a 14 x 14 látice design. Recombination of the superior progenies was processed within the same year in order to get one cycle per year. The values of the genetic parameters decreased from the original cycle to cycle I, keeping at cycle II similar magnitudes of cycle I. The high magnitudes of the genetic parameters, the high productivity means of progenies, and the averaged gain expected from the selection among and within progenies per selection cycle (12.3\%) show the high potential of the population to respond to selection, which will permit to attain a higher yielding population, better adapted to the regional environment. The high progeny $x$ location interaction showed the importance for progeny evaluation in more than one location, to increase the efficiency of the selection process and to obtain more accurate estimates of variance components.
\end{abstract}

Index terms: Zea mays, genetic parameters, genetic variation, progeny testing, selection, breeding methods.

\footnotetext{
${ }^{1}$ Aceito para publicação em 8 de dezembro de 1999.

${ }^{2}$ Eng. Agrôn., M.Sc., Embrapa-Centro de Pesquisa Agropecuária dos Tabuleiros Costeiros (CPATC), Caixa Postal 44, CEP 49001-970 Aracaju, SE. E-mail: helio@cpatc.embrapa.br, lurdinha@cpatc.embrapa.br ${ }^{3}$ Eng. Agrôn., Ph.D., Embrapa-Centro Nacional de
}

Pesquisa de Milho e Sorgo (CNPMS), Caixa Postal 151, CEP 35701-970 Sete Lagoas, MG. E-mail: guimaraes@cnpms.embrapa.br, xavier@cnpms.embrapa.br

${ }^{4}$ Eng. Agrôn., M.Sc., Escola de Agronomia, Universidade Federal da Bahia (UFBA), CEP 44380-000 Cruz das Almas, BA.

Pesq. agropec. bras., Brasília, v.35, n.8, p.1621-1628, ago. 2000 


\section{INTRODUÇÃO}

Magnavaca et al. (1988) ressaltaram que genótipos de milho contendo o gene opaco-2, que aumenta o teor de lisina na proteína, não foram bem aceitos no Brasil, em razão de apresentarem endosperma mole e farináceo, que resulta em menor densidade do grão, menor produtividade e maior teor de umidade na colheita. Após terem sido superados os problemas associados ao gene opaco-2, mediante a obtenção de compostos de base genética ampla, onde foi possível selecionar cultivares de milho estáveis, tão produtivas quanto às de milho comum, apresentando grãos de mesmo valor energético e endosperma vítreo, despertou-se o interesse pela utilização desse germoplasma.

Interessados em avaliar populações de alta qualidade protéica em diferentes regiões do Brasil, Magnavaca et al. (1988) introduziam 23 populações do Centro Internacional de Mejoramiento de Maiz y Trigo (CIMMYT), constatando a alta produtividade de espiga dessas populações, criando perspectivas de serem obtidas delas, cultivares de alta qualidade protéica, aceitas pelos agricultores quanto ao fenótipo do grão.

A utilização de genótipos de alta qualidade protéica no Nordeste brasileiro reveste-se de grande importância, por ser esta uma região com sérios problemas de desnutrição. Sabe-se que o consumo do milho nessa ampla região é bastante significativo, e, embora este cereal represente importante fonte de energia, apresenta baixa qualidade biológica, por ser a zeína, sua proteína mais abundante, deficiente nos aminoácidos essenciais triptofano e lisina, tornando imprescindível a adição de outra fonte protéica para melhorar a sua qualidade alimentar, tanto para uso humano quanto animal. $\mathrm{O}$ desenvolvimento e a difusão de cultivares de milho de alta qualidade protéica, de alto potencial para a produtividade e adaptadas às condições edafoclimáticas do Nordeste brasileiro poderão proporcionar melhoria na qualidade alimentar da população carente dessa região.

Neste contexto, a Embrapa-Centro de Pesquisa Agropecuária dos Tabuleiros Costeiros vem desenvolvendo um programa de melhoramento genético intrapopulacional com a população de milho CMS-52, detentora de alta qualidade protéica e de atributos agronômicos desejáveis, tais como precocidade, baixa altura da planta e da inserção da primeira espiga, e boa capacidade produtiva, verificados em trabalhos de competição de cultivares realizados na região (Cardoso et al., 1997; Carvalho et al., 1998b, 1998d). Utilizou-se o método de seleção entre e dentro de progênies de meios-irmãos que vem sendo praticado com sucesso, conforme assinalam Paterniani $(1967,1968)$, Zinsly (1968), Segovia (1976), Sawazaki (1979) e Hallauer \& Miranda Filho (1988), que em um levantamento realizado no exterior envolvendo 99 trabalhos, comprovaram a eficiência desse método de seleção, concluindo que ele é capaz de manter suficiente variabilidade genética para propiciar ganhos no decorrer dos ciclos subseqüentes de seleção. Outros trabalhos têm demonstrado a eficiência deste método, enfocando os ganhos genéticos com vistas às produtividades de grãos e à variância genética aditiva (Paterniani, 1967; Webel \& Lonquist, 1967, citados por Paterniani, 1968; Carvalho et al., 1994, 1995, 1998a).

Com relação à variância genética aditiva, Ramalho (1977) encontrou valores que oscilaram de 41,0 a $758,0$ (g/planta $)^{2}$, em um levantamento realizado no Brasil até 1976. No exterior, em um levantamento envolvendo 99 trabalhos, Hallauer \& Miranda Filho (1988) encontraram um valor médio de 469,1 (g/planta) ${ }^{2}$. Valores mais expressivos dessa variância genética aditiva têm sido encontrados em apenas um local, conforme relatados por Lordello (1982), com as populações Piranão VD-2 e Piranão VF-1, na ordem de $1.995,0$ (g/planta $)^{2}$ e $1.725,8$ (g/planta $)^{2}$, respectivamente, e por Carvalho et al. (1998c), que obtiveram $1.827,1$ (g/planta $)^{2}$ e 1.273,4 (g/planta $)^{2}$ nos ciclos VI e VII, respectivamente, com a cultivar BR 5028-São Francisco. Hallauer \& Miranda Filho (1988) comentam que as estimativas de parâmetros genéticos e fenotípicos obtidos em apenas um local podem estar superestimados, por serem influenciados pela interação progênies x locais.

O trabalho teve por objetivo avaliar os parâmetros genéticos da população CMS-52 submetida a três ciclos de seleção entre e dentro de progênies de meios-irmãos.

\section{MATERIAL E MÉTODOS}

No ano agrícola de 1994, a Embrapa-Centro de Pesquisa Agropecuária dos Tabuleiros Costeiros (CPATC) rece- 
beu uma amostra representativa da população CMS-52, da Embrapa-Centro Nacional de Pesquisa de Milho e Sorgo (CNPMS), visando iniciar o programa de melhoramento genético desta população para a Região Nordeste. Tratase de uma população de polinização aberta, de porte baixo da planta, de inserção baixa da primeira espiga, de ciclo superprecoce, e de grãos semiduros com coloração vermelha. Esta população foi introduzida do Centro Internacional de Mejoramiento de Maiz y Trigo (CIMMYT), através da Embrapa-CNPMS. Nesse ano (1994), foi plantada uma área de $2.000 \mathrm{~m}^{2}$ com a população CMS-52 no município de Neópolis, obtendo-se 196 progênies de meiosirmãos, as quais foram selecionadas observando-se os aspectos de competitividade, uniformidade da altura das plantas e espigas, prolificidade, precocidade, empalhamento, coloração de grãos, produtividade, e determinação dos teores de triptofano e de lisina na proteína do endosperma. A seguir, foram realizados o ciclo original de seleção (municípios de Neópolis e Lagarto, 1995), ciclo I (municípios de Cruz das Almas e Nossa Senhora das Dores, 1996) e ciclo II (municípios de Nossa Senhora das Dores e Umbaúba, 1997).

Nos três ciclos de seleção, as progênies foram avaliadas em látice simples 14 x 14. Cada parcela constou de uma fileira de 5,0 m de comprimento, com espaços de $0,90 \mathrm{~m}$ entre fileiras e 0,20 m entre covas, nas fileiras. Foram colocadas três sementes por cova, deixando-se duas plantas por cova, após o desbaste. Após a realização dos ensaios, dentro de cada ano agrícola, as quarenta progênies com as melhores produtividades média de espigas foram submetidas à análise de laboratório, na Embrapa-CNPMS, para determinação dos teores de proteína, triptofano e lisina, e selecionadas 15 progênies a cada ciclo de seleção, correspondendo a uma intensidade de seleção de $8 \%$, entre progênies. As progênies selecionadas foram recombinadas em lotes isolados por despendoamento, dentro do mesmo ano agrícola, onde foram selecionadas 196 novas progênies de meios-irmãos para iniciar o ciclo seguinte de seleção, correspondendo a uma intensidade de seleção de $13 \%$, dentro de progênies. Todos os ensaios e campos de recombinação receberam uma adubação de $80 \mathrm{~kg} \mathrm{ha}^{-1}$ de N e $80 \mathrm{~kg} \mathrm{ha}^{-1}$ de $\mathrm{P}_{2} \mathrm{O}_{5}$, nas formas de uréia e superfosfato simples. Todo o $\mathrm{P}$ foi aplicado no fundo dos sulcos, na semeadura, e o N, em cobertura, na terceira e quarta semana após o plantio.

Em todos os ensaios foram tomados os pesos de espigas, os quais foram ajustados para o nível de $15 \%$ de umidade. Realizou-se, inicialmente, a análise de variância por local, obedecendo-se ao esquema em látice. Posteriormente, procedeu-se à análise de variância conjunta, a partir das médias ajustadas de tratamentos. Os quadrados médios das análises de variância conjuntas foram ajustadas para o nível de indivíduos, obtendo-se, assim, todas as variâncias nesse nível e expressas em (g/planta) ${ }^{2}$, conforme Vencovsky (1978).

Embora as análises tenham sido feitas em látices, as estimativas dos componentes da variância foram baseadas nas esperanças dos quadrados médios para blocos casualizados, usando os quadrados médios de tratamentos ajustados, e do erro efetivo do látice, conforme metodologia descrita por Vianna \& Silva (1978). As estimativas da variância genética aditiva $\left(\hat{\sigma}_{\mathrm{A}}^{2}\right)$, da variância fenotípica nas próprias plantas $\left(\hat{\sigma}_{\mathrm{F}}^{2}\right)$ e entre médias de progênies $\left(\hat{\sigma}_{\overline{\mathrm{F}}}^{2}\right)$, dos coeficientes de herdabilidade no sentido restrito nas médias de progênies $\left(h^{2} m\right)$ e de plantas $\left(h^{2}\right)$ foram obtidas pelas seguintes expressões (Vencovsky \& Barriga, 1992):

$$
\begin{aligned}
& \hat{\sigma}_{\mathrm{A}}^{2}=4 \hat{\sigma}_{\mathrm{P}}^{2}, \\
& \hat{\sigma}_{\mathrm{F}}^{2}=\hat{\sigma}_{\mathrm{P}}^{2}+\hat{\sigma}_{\mathrm{C}}^{2}+\hat{\sigma}_{\mathrm{d}}^{2}, \\
& \hat{\sigma}_{\overline{\mathrm{F}}}^{2}=\hat{\sigma}_{\mathrm{P}}^{2}+\frac{\hat{\sigma} \mathrm{e}^{2}}{\mathrm{r}}+\frac{\hat{\sigma} \mathrm{d}^{2}}{\mathrm{nr}}, \\
& \mathrm{h}_{\mathrm{m}}^{2}=\hat{\sigma}_{\mathrm{P}}^{2} / \hat{\sigma}_{\overline{\mathrm{F}}}^{2} \mathrm{e} \\
& \mathrm{h}^{2}=\hat{\sigma}_{\mathrm{A}}^{2} / \hat{\sigma}_{\mathrm{F}}^{2} .
\end{aligned}
$$

$\mathrm{O}$ índice de variação $\mathrm{b}$ foi determinado pelo quociente $\mathrm{CV}_{\mathrm{g}} / \mathrm{CV}_{\mathrm{e}}$, em que $\mathrm{CV}_{\mathrm{g}}=\sigma_{\mathrm{P}} / \overline{\mathrm{X}}$ é o coeficiente de variação genotípico, e o $\mathrm{CV}_{\mathrm{e}}$ é o coeficiente de variação experimental.

O progresso esperado, quando se utiliza a seleção entre e dentro de progênies de meios-irmãos, dentro do mesmo ano agrícola, foi estimado pela fórmula:

$$
\mathrm{Gs}=\frac{\mathrm{K}_{1} \cdot \hat{\sigma}_{\mathrm{P}}^{2}}{\sigma_{\overline{\mathrm{F}}}}+\frac{\mathrm{K}_{2} \cdot(3 / 8) \hat{\sigma}_{\mathrm{A}}^{2}}{\sigma_{\mathrm{d}}} \text {, em que, }
$$

$\mathrm{K}_{1}$ : diferencial de seleção estandardizado, que depende da intensidade de seleção entre progênies $=8 \%(1,8583)$; $\mathrm{K}_{2}$ : diferencial de seleção estandardizado, que depende da intensidade de seleção dentro de progênies $=15 \%(1,5544)$; $\sigma_{\mathrm{d}}$ : desvio-padrão fenotípico dentro de progênies de meios-irmãos.

\section{RESULTADOS E DISCUSSÃO}

Foram detectadas diferenças altamente significativas entre as progênies, em todos os ciclos de seleção, o que revela a presença de variabilidade genética entre elas (Tabela 1). A presença da interação 
progênies x locais evidencia um comportamento inconsistente entre as progênies em face das variações ambientais. A importância dessa interação vem sendo observada em diversos trabalhos, com diversas populações; entre eles, Pacheco (1987) com o ciclo I da população CMS-39, em dois locais; Carvalho et al. (1994), com progênies de meios-irmãos dos ciclos I e II da cultivar BR 5028; Carvalho et al. (1995), do ciclo I da cultivar BR 5033; e Carvalho et al. (1998c), dos ciclos VIII e IX da cultivar BR 5028, em dois locais do Estado de Sergipe. Os coeficientes de variação experimental foram baixos, revelando a boa precisão dos experimentos (Pimentel-Gomes, 1985).

As produtividades médias das progênies avaliadas, nos três ciclos de seleção foram de $4.511 \mathrm{~kg} \mathrm{ha}^{-1}$, $6.942 \mathrm{~kg} \mathrm{ha}^{-1}$ e $4.602 \mathrm{~kg} \mathrm{ha}^{-1}$, com média de $5.352 \mathrm{~kg} \mathrm{ha}^{-1}$, atestando o bom potencial para a produtividade da população CMS-52 (Tabela 2). As produtividades médias dos ciclos foram menores que as registradas nas testemunhas BR 5033 e BR 5028, ocorrendo, no entanto, um acréscimo nas produtividades ajustadas desses ciclos, em relação às testemunhas, à medida que se avançaram os ciclos de seleção. As progênies selecionadas superaram as testemunhas BR $5033 \mathrm{em} 7,8 \%, 8,4 \%$ e 11,2\% e, BR 5028 em 3,5\%, 6,8\% e 8,7\%, respectivamente, nos ciclos original, I e II. Percebe-se, portanto, que as amplitudes das produtividades mostram também a eficiência do método de seleção utilizado, uma vez que progênies selecionadas cada vez mais produtivas foram obtidas com o desenvolver dos ciclos de seleção.
As estimativas dos parâmetros genéticos, em todos os ciclos de seleção, são apresentados na Tabela 3. Verificou-se uma redução nas variâncias genéticas entre progênies e aditiva do ciclo original para o ciclo I, permanecendo as mesmas no ciclo II com magnitudes semelhantes às do ciclo I. Essa tendência foi também observada em trabalhos similares de melhoramento (Paterniani, 1968; Carvalho et al., 1994, 1995, 1998a), e explicada por Ramalho (1977) como decorrente da utilização máxima da variabilidade livre no ciclo original, que corresponde à segregação entre blocos gênicos, e que a partir do primeiro ciclo é utilizada a variabilidade genética latente, gradativamente, através da permuta genética. Estimativas obtidas neste trabalho são concordantes com as estimativas obtidas em diversas populações de milho brasileiras (Ramalho, 1977; Aguiar, 1986; Pacheco, 1987; Carvalho et al., 1994, 1995, 1998a, 1998c). Segundo Paterniani (1968), é do máximo interesse que a variância aditiva permaneça tão alta quanto possível para permitir a obtenção de progressos significativos por seleção. De acordo com o referido autor, o método de seleção entre e dentro de progênies de meios-irmãos reduz muito essa variância, sobretudo no primeiro ciclo de seleção.

As estimativas da variância da interação progênies $x$ locais evidencia grande divergência entre os locais e um comportamento diferenciado das progênies nesses locais, principalmente, nos ciclos original e I de seleção. Para Hallauer \& Miranda Filho (1988), esse componente das variâncias pode atingir mais de $50 \%$ da estimativa da variância gené-

TABELA 1. Quadrados médios das análises de variância conjunta e coeficientes de variação em três ciclos de seleção de progênies da população de milho CMS-52²

\begin{tabular}{lcccc}
\hline Fonte de variação & Grau de liberdade & \multicolumn{3}{c}{ Quadrado médio } \\
\cline { 3 - 5 } & & Ciclo original & Ciclo I & Ciclo II \\
\hline Progênies & 195 & $659,79^{* *}$ & $451,62^{* *}$ & $294,27^{* *}$ \\
Progênies x locais & 195 & $389,30^{* *}$ & $318,54 * *$ & $159,43^{* *}$ \\
Erro efetivo médio & 390 & 119,41 & 102,68 & 106,95 \\
\hline Médias & & 86,70 & 125,10 & 86,28 \\
C.V. $(\%)$ & 12,40 & 8,10 & 11,98 \\
\hline
\end{tabular}

${ }^{1}$ Ciclo original: Neópolis e Lagarto, 1995; ciclo I: Cruz das Almas e Nossa Senhora das Dores, 1996; ciclo II: Umbaúba e Nossa Senhora das Dores, 1997.

** Significativo a $1 \%$ de probabilidade pelo teste $\mathrm{F}$. 
tica entre progênies, e as estimativas dos parâmetros genéticos e fenotípicos obtidos em apenas um local são superestimados, pela existência do componente da variação resultante da interação progênie x local, que não pode ser isolado.

Os valores dos coeficientes de herdabilidade no sentido restrito com médias de progênies de meios- irmãos $\left(h^{2} \mathrm{~m}\right)$ superaram os obtidos nas próprias plantas $\left(h^{2}\right)$, em todos os ciclos de seleção, o que indica que a seleção com médias de progênies de meios-irmãos deve ser mais eficiente que a seleção massal. Essa evidência tem sido observada em outros trabalhos (Aguiar, 1986; Pacheco, 1987; Sawazaki, 1979; Carvalho et al., 1994, 1995, 1998a,

TABELA 2. Produtividade média das progênies de milho avaliadas e selecionadas nos ciclos original, I e II de seleção e das testemunhas BR 5033 e BR 5028, e médias ajustadas das progênies avaliadas em relação às testemunhas. Região Nordeste do Brasil, 1995 a 1997.

\begin{tabular}{|c|c|c|c|c|c|c|}
\hline \multirow[t]{2}{*}{$\mathrm{Ciclo}^{1}$} & \multirow[t]{2}{*}{ Material } & \multirow{2}{*}{$\begin{array}{c}\text { Produtividade } \\
\text { média } \\
\left(\mathrm{kg} \mathrm{ha}^{-1}\right)\end{array}$} & \multicolumn{2}{|c|}{$\begin{array}{l}\text { Médias ajustadas em relação } \\
\text { às testemunhas }\end{array}$} & \multicolumn{2}{|c|}{$\begin{array}{l}\text { Porcentagem em relação } \\
\text { às testemunhas }\end{array}$} \\
\hline & & & BR 5033 & BR 5028 & BR 5033 & BR5028 \\
\hline \multirow[t]{4}{*}{ Original } & BR 5033 & 5.490 & \multirow{4}{*}{5.016} & \multirow{4}{*}{4.948} & 100,0 & - \\
\hline & BR 5028 & 5.720 & & & - & 100,0 \\
\hline & Progênies avaliadas & 4.511 & & & 82,2 & 78,9 \\
\hline & Progênies selecionadas & 5.920 & & & 107,8 & 103,5 \\
\hline \multirow[t]{4}{*}{ I } & BR 5033 & 7.490 & \multirow{4}{*}{5.447} & \multirow{4}{*}{5.502} & 100,0 & - \\
\hline & BR 5028 & 7.597 & & & - & 100,0 \\
\hline & Progênies avaliadas & 6.942 & & & 92,7 & 91,4 \\
\hline & Progênies selecionadas & 8.116 & & & 108,4 & 106,8 \\
\hline \multirow[t]{4}{*}{ II } & BR 5033 & 5.006 & \multirow{4}{*}{5.591} & \multirow{4}{*}{5.603} & 100,0 & - \\
\hline & BR 5028 & 5.156 & & & - & 100,0 \\
\hline & Progênies avaliadas & 4.602 & & & 92,0 & 89,2 \\
\hline & Progênies selecionadas & 5.606 & & & 112,0 & 108,7 \\
\hline
\end{tabular}

${ }^{1}$ Ciclo original: Neópolis e Lagarto, 1995; ciclo I: Cruz das Almas e Nossa Senhora das Dores, 1996; ciclo II: Umbaúba e Nossa Senhora das Dores, 1997.

TABELA 3. Estimativas obtidas referentes às variâncias genéticas entre progênies $\left(\sigma_{\mathrm{p}}^{2}\right)$, aditiva $\left(\sigma_{\mathrm{A}}^{2}\right)$ e da interação progênies $x$ locais $\left(\sigma_{\text {pxl }}^{2}\right)$, coeficientes de herdabilidade no sentido restrito com médias de progênies $\left(h^{2} m\right)$, para a seleção massal $\left(h^{2}\right)$ e de variação genética $(\mathrm{CVg})$ e ganhos genéticos entre e dentro de progênies de meios-irmãos (Gs), considerando o caráter peso de espiga, para a população de milho CMS-52. Região Nordeste do Brasil, 1995 a 1997.

\begin{tabular}{|c|c|c|c|c|c|c|c|c|c|c|c|}
\hline \multirow[t]{2}{*}{ Ciclo $^{1}$} & $\sigma_{p}^{2}$ & $\sigma_{\mathrm{A}}^{2}$ & $\sigma_{\mathrm{pxl}}^{2}$ & $\mathrm{~h}_{\mathrm{m}}^{2}$ & $\mathrm{~h}^{2}$ & $\mathrm{CVg}$ & \multirow[t]{2}{*}{$\mathrm{b}$} & \multicolumn{2}{|c|}{$\mathrm{Gs}^{2}$ entre } & \multicolumn{2}{|c|}{ Gs dentro } \\
\hline & ------ & (g/plan & 1) $)^{2}$------ & ------- & $(\%)-$ & -- & & (g/planta) & $(\%)$ & (g/planta) & $(\%)$ \\
\hline Original & 67,6 & 270,5 & 134,9 & 41,0 & 23,6 & 9,3 & 0,8 & 9,74 & 11,01 & 5,64 & 7,41 \\
\hline I & 33,3 & 133,2 & 107,1 & 29,5 & 14,2 & 4,6 & 0,6 & 5,79 & 4,64 & 3,01 & 2,41 \\
\hline II & 33,7 & 134,8 & 26,2 & 45,8 & 15,3 & 6,7 & 0,6 & 7,27 & 8,42 & 2,60 & 3,01 \\
\hline
\end{tabular}

${ }^{1}$ Ciclo original: Neópolis e Lagarto, 1995; ciclo I: Cruz das Almas e Nossa Senhora das Dores, 1996; ciclo II: Umbaúba e Nossa Senhora das Dores, 1997.

2 Para cálculo dos ganhos considerou-se a relação $\sigma_{\mathrm{d}}^{2}=10 \sigma^{2}$, conforme sugestão de Gardner (1961). 
1998c). Os valores dos coeficientes de variações genéticas, à semelhança dos coeficientes de herdabilidade e do índice $b$, refletem uma queda da variabilidade do ciclo original para o I, à semelhança do ocorrido em relação aos demais parâmetros, refletindo maior variação entre as progênies do ciclo original quando comparadas com as progênies dos ciclo I e II, e suas magnitudes possibilitaram a obtenção de ganhos genéticos no decorrer dos ciclos de seleção.

As estimativas dos progressos genéticos esperados com a seleção entre e dentro das progênies, nos ciclos original, I e II, foram, respectivamente, $18,42 \%, 7,05 \%$ e $11,43 \%$, com média de $12,30 \%$ (Tabela 3 ), sendo compatíveis com os obtidos por Carvalho et al. (1994, 1998a), nos ciclos original e I de seleção com as cultivares BR 5028, BR 5011 e superiores aos registrados por Paterniani (1968), Cunha (1976), Segovia (1976), Lima (1977), Aguiar (1986), Pacheco (1987), Carvalho et al. (1995), expressando, mais uma vez, o potencial genético dessa população em responder à seleção com vistas ao aumento da produtividade.

Considerando que as diferenças entre as médias das progênies das testemunhas comuns BR $5033 \mathrm{e}$ BR 5028 refletiam as diferenças ambientais e as interações de um ciclo para outro, pode-se ajustar as médias dos ciclos das progênies avaliadas, para tornálas compatíveis. Desta forma, o ganho acumulado obtido nos três ciclos de seleção foi de $575 \mathrm{~kg} \mathrm{ha}^{-1}$, equivalente a $11,1 \%$, o que fornece um ganho ciclo ano de $192 \mathrm{~kg} \mathrm{ha}^{-1}$, correspondente a 3,74 em relação à testemunha BR 5033. Da mesma forma, obteve-se um ganho acumulado de $655 \mathrm{~kg} \mathrm{ha}^{-1}$, equivalente a $13,2 \%$, o que fornece um ganho obtido ciclo por ano de $218 \mathrm{~kg} \mathrm{ha}^{-1}$, correspondendo a $4,41 \%$ com relação à testemunha BR 5028.

Segundo Sawazaki (1979), na maioria dos casos existe concordância entre os valores do ganho obtido e do ganho esperado, a exemplo de Segovia (1976), que obteve um ganho esperado de $3,25 \%$ e um observado de $3,30 \%$, discordando dos resultados do presente trabalho, em que o ganho médio esperado por ciclo foi de $12,30 \%$, e os ganhos obtidos em relação às testemunhas BR 5033 e BR 5028 foram de $3,70 \%$ e $4,40 \%$, respectivamente. Valores mais discordantes foram detectados por Miranda Filho (1977, 1979), que obteve progresso esperado de $8,8 \%$ e obtido de 1,9\%, nos oito primeiros ciclos de seleção com o milho IAC-I.

Com relação à qualidade biológica dos grãos, as progênies selecionadas apresentaram 10,92\%, 10,6\% e $9,74 \%$ de proteína, nos ciclos original, I e II de seleção, respectivamente, com média de 10,42\%. Os valores obtidos quanto a triptofano e lisina na proteína do endosperma, foram de $0,87 \%$ e $3,85 \%$, no ciclo original; $0,89 \%$ e $3,99 \%$, no ciclo I; $0,83 \%$ e $3,93 \%$, no ciclo II. As médias encontradas no tocante a esses valores nos três ciclos de seleção foram de $0,86 \%$ e $3,92 \%$, respectivamente; sendo que esses valores foram superiores aos encontrados nas cultivares BR 451 ( $0,80 \%$ de triptofano e 3,62\% de lisina), e compatíveis com os detectados na cultivar BR 473 $(0,90 \%$ de triptofano e $4,0 \%$ de lisina). As cultivares-testemunhas (BR 5033 e BR 5028) mostraram valores de $0,64 \%$ e $2,63 \%$ de triptofano e lisina na proteína, respectivamente. Os valores de triptofano e lisina no grão foram de $0,091 \%$ e $0,40 \%$, no ciclo original; $0,093 \%$ e $0,42 \%$, no ciclo I; $0,080 \%$ e $0,38 \%$, no ciclo II. As médias detectadas nos três ciclos de seleção foram de $0,088 \%$ e $0,40 \%$ de triptofano e lisina no grão, respectivamente, sendo semelhantes aos encontrados no híbrido BR 2121, de alta qualidade protéica $(0,09 \%$ de triptofano e $0,40 \%$ de lisina). Esses valores confirmam o alto teor protéico da população CMS-52.

Considerando a variabilidade detectada por meio das estimativas dos parâmetros genéticos, e o fato de essa população apresentar alto potencial para a produtividade, acredita-se que substanciais progressos serão obtidos com o desenvolver de novos ciclos de seleção.

\section{CONCLUSÕES}

1. A alta variabilidade genética mostrada pela população CMS-52, e as altas médias de produtividade das progênies evidenciam o grande potencial dessa população em um programa de melhoramento.

2. O progresso médio esperado com a seleção entre e dentro de progênies, por ciclo de seleção, é de $12,3 \%$.

3. A estimativa da variância da interação progênies x locais mostra a importância de se realizar a avaliação em mais de um local, para melhorar a efi- 
ciência do processo seletivo e permitir a obtenção de estimativas mais consistentes dos componentes da variância.

\section{REFERÊNCIAS}

AGUIAR, P.A. Avaliação de progênies de meios-irmãos de milho CMS 39 em diferentes condições de ambientes. Lavras : ESAL, 1986. 68p. Dissertação de Mestrado.

CARDOSO, M.J.; CARVALHO, H.W.L. de; PACHECO, C.A.A.P.; SANTOS, M.X. dos; LEAL, M. de L. da $\mathrm{S}$. Adaptabilidade e estabilidade de cultivares de milho no Estado do Piauí, no biênio 1993/94. Revista Científica Rural, Bagé, v.2, n.1, p.35-44, 1997.

CARVALHO, H.W.L. de; PACHECO, C.A.A.P.; SANTOS, M.X. dos; GAMA, E.E.G. e; MAGNAVACA, R. Potencial genético da população de milho (Zea mays L.) CMS 53 para fins de melhoramento no Nordeste brasileiro. Ciência e Prática, Lavras, v.19, n.1, p.37-42, 1995.

CARVALHO, H.W.L. de; PACHECO, C.A.A.P.; SANTOS, M.X. dos; GAMA, E.E.G. e; MAGNAVACA, R. Três ciclos de seleção entre e dentro de famílias de meios-irmãos na população de milho BR 5011 no Nordeste brasileiro. Pesquisa Agropecuária Brasileira, Brasília, v.33, n.5, p.713-720, maio 1998a.

CARVALHO, H.W.L. de; PACHECO, C.A.A.P.; SANTOS, M.X. dos; GAMA, E.E.G. e; MAGNAVACA, R. Três ciclos de seleção entre e dentro de progênies de meios-irmãos na população de milho BR 5028São Francisco, no Nordeste brasileiro. Pesquisa Agropecuária Brasileira, Brasília, v.29, n.11, p.1727-1733, nov. 1994.

CARVALHO, H.W.L. de; PACHECO, C.A.A.P.; SANTOS, M.X. dos; LEAL, M. de L. da S. Estabilidade de cultivares de milho no Estado de Sergipe. Revista Científica Rural, Bagé, v.3, n.1, p.15-22, 1998b.

CARVALHO, H.W.L. de; SANTOS, M.X. dos; LEAL, M. de L. da S.; PACHECO, C.A.A.P. Melhoramento genético da variedade de milho BR 5028-São Francisco no Nordeste brasileiro. Pesquisa Agropecuária Brasileira, Brasília, v.33, n.4, p.441-448, abr. 1998c.

CARVALHO, H.W.L. de; SANTOS, M.X. dos; LEAL, M. de L. da S.; PACHECO, C.A.A.P.; CARVALHO, B.C.L.; LIRA, M.A. Adaptabilidade e estabilidade de cultivares de milho no Nordeste brasileiro no ano de 1995. Revista Científica Rural, Bagé, v.3, n.1, p.8-14, 1998d.

CUNHA, M.A. Seleção entre e dentro de famílias de meios-irmãos no milho (Zea mays L.) ESALQ HV-1. Piracicaba : ESALQ, 1976. 84p. Tese de Doutorado.

GARDNER, C.O. An evaluation of effects of mass selection and seed irradiation with thermal neutrons on yield of corn. Crop Science, Madison, v.1, p.241245,1961

HALLAUER, A.R.; MIRANDA FILHO, J.B. Quantitative genetics in maize breeding. 2.ed. Ames : Iowa State University Press, 1988. 468p.

LIMA, M. Seleção entre e dentro de famílias de meios-irmãos na população de milho (Zea mays $\mathrm{L}_{\text {.) }}$ ESALQ VD-2. Piracicaba : ESALQ, 1977. 71p. Dissertação de Mestrado.

LORDELLO, J.A.C. Parâmetros genéticos das populações de milho Piranão VD-2 e Piranão VF-1. Piracicaba : ESALQ, 1982. 62p. Dissertação de Mestrado.

MAGNAVACA, R.; PAIVA, E.; WINKLER, E.I.; CARVALHO, H.W.L. de; SILVA FILHO, M. de C.; PEIXOTO, M.J.V.V.D. Avaliação de populações de milho de alta qualidade protéica. Pesquisa Agropecuária Brasileira, Brasília, v.23, n.11, p.1263-1268, nov. 1988.

MIRANDA FILHO, J.B. Avaliação de famílias de meios-irmãos na população de milho ESALQ PB-1. Piracicaba : ESALQ, 1977. p.80-94. (Relatório Técnico Científico, 11).

MIRANDA FILHO, J.B. Avaliação de famílias de meios-irmãos do segundo ciclo de seleção da população ESALQ PB-1 de milho. Piracicaba : ESALQ, 1979. p.149-158. (Relatório Técnico Científico, 13).

PACHECO, C.A.A.P. Avaliação de progênies de meios-irmãos na população de milho CMS-39 em diferentes condições de ambientes: $2^{\circ}$ ciclo de seleção. Lavras : ESAL, 1987. 100p. Dissertação de Mestrado.

PATERNIANI, E. Avaliação de método de seleção entre e dentro de famílias de meios-irmãos no melhoramento de milho (Zea mays L.). Piracicaba : ESALQ, 1968. 92p. Dissertação de Mestrado.

PATERNIANI, E. Selection among and within half-sib families in a Brazilian population of maize (Zea mays L.). Crop Science, Madison, v.7, n.3, p.212216, 1967.

Pesq. agropec. bras., Brasília, v.35, n.8, p.1621-1628, ago. 2000 
PIMENTEL-GOMES, F. Curso de estatística experimental. 9.ed. São Paulo : Nobel, 1985. 450p.

RAMALHO, M.A.P. Eficiência relativa de alguns processos de seleção intrapopulacional no milho baseados em famílias não endógamas. Piracicaba : ESALQ, 1977. 122p. Dissertação de Mestrado.

SAWAZAKI, E. Treze ciclos de seleção entre e dentro de também de meios-irmãos para a produção de grãos no milho IAC-Maia. Piracicaba : ESALQ, 1979. 99p. Dissertação de Mestrado.

SEGOVIA, R.T. Seis ciclos de seleção entre e dentro de familiar de meios-irmãos no milho (Zea mays L.) Centralmex. Piracicaba : ESALQ, 1976. 98p. Tese de Doutorado.
VENCOVSKY, R. Herança quantitativa. In: PATERNIANI, E. (Ed.). Melhoramento e produção do milho no Brasil. Piracicaba : ESALQ, 1978. p.122-201.

VENCOVSKY, R.; BARRIGA, P. Genética biométrica no fitomelhoramento. Ribeirão Preto : Sociedade Brasileira de Genética, 1992. 496p.

VIANNA, R.T.; SILVA, J.C. Comparação de três métodos de análise de variância em experimentos em "látice" em milho (Zea mays L.). Experientiae, Viçosa, v.24, p.21-41, 1978.

ZINSLY, J.R. Estudo comparativo entre a seleção massal e a seleção entre e dentro de famílias de meios-irmãos em milho (Zea mays L.). Piracicaba : ESALQ, 1969. 52p. Tese de Doutorado. 